\title{
A hypogammaglobulinaemic man with respiratory failure
}

\author{
W A C Sewell, S E Marshall, C G Mullighan, A G Bird
}

A 65-year-old man with a long-standing clinical history of bronchiectasis and sarcoid-like skin lesions had been diagnosed as having common variable immunodeficiency (CVID) 4 years previously, and began treatment with regular intravenous immunoglobulin (IVIG) to good effect. Seven months before admission he developed a Coombs' positive haemolytic anaemia (haemoglobin $9.3 \mathrm{~g} / \mathrm{l}$ ) with splenomegaly and lymphadenopathy. He received three units of blood, his IVIG dose was increased, but he required oral prednisolone $40 \mathrm{mg} /$ day to control his anaemia. A month before admission his visual acuity deteriorated in the right eye, and investigations revealed a granulomatous choroiditis, inaccessible to biopsy. Whilst this was being investigated, he developed dyspnoea at rest, with a cough productive of white sputum, and no haemoptysis. On examination he was unwell, cyanosed, plethoric and with bruised skin. Chest examination showed dullness at both bases, associated with inspiratory and expiratory crackles. Investigations showed him to be hypoxic, with a markedly reduced diffusion capacity ( $\mathrm{DL}_{\mathrm{Co}} 28 \%$ predicted, $\mathrm{K}_{\mathrm{Co}} 38 \%$ predicted). Only normal respiratory flora, and no acid/alcohol-fast bacteria were isolated from sputum cultures. Imaging with high resolution computed tomography (CT) showed ground-glass opacification in both lung fields with multifocal consolidation in the right upper lobe. Bronchoscopy of this area was normal; lavage showed a minor inflammatory cell infiltrate with no malignancy. The lavage culture was negative for bacteria, fungus, acid/alcohol-fast bacteria, and Pneumocystis carinii, and cytological examination was normal. There was no improvement on intravenous antibiotics, so an open lung biopsy was performed. Characteristic lesions were found (figure).

\section{Department of Clinical Immunology, Royal Free Hospital, London NW3 2PF, UK \\ W A C Sewell \\ Department of Immunology, The Churchill Hospital, Headington, Oxford OX3 7LJ, UK \\ S E Marshall \\ C G Mullighan \\ A G Bird}

Accepted 10 March 1998

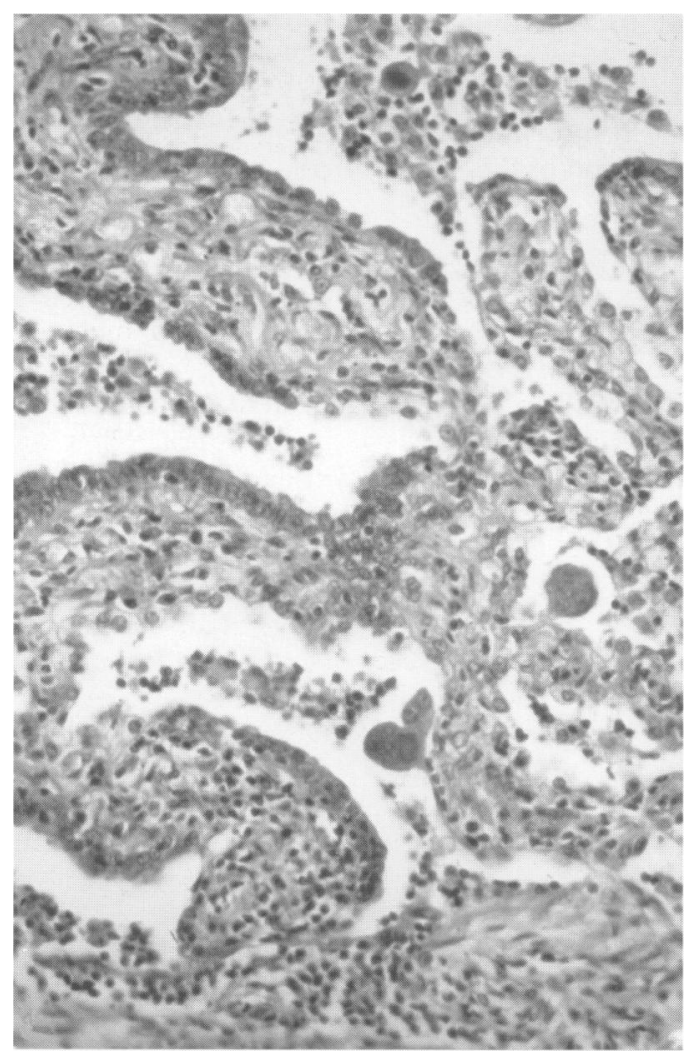

\section{Questions}

1 What are the findings on the biopsy and what organism are they associated with?

2 Of what use is serology in making a diagnosis in this patient?

3 What should the infection be treated with? 
Answers

QUESTION 1

The biopsy shows an organising pneumonia with owl's eye inclusion bodies characteristic of cytomegalovirus (CMV) pneumonitis. ${ }^{1} \mathrm{CMV}$ infection was confirmed immunochemically.

QUESTION 2

Serology is of no use in patients with CVID: they do not make adequate IgG responses to infections, and their circulating IgG comes from the pooled normal human immunoglobulin given as replacement therapy.

QUESTION 3

Intravenous ganciclovir is the treatment of choice, with adequate replacement of immunoglobulin therapy in the hypogammaglobulinaemic patient. CMV-specific immunoglobulin is available for immunocompetent adults, but the anti-CMV titre overlaps with that in batches of standard IVIG so was not used in this patient.

\section{Discussion}

Patients with CVID are hypogammaglobulinaemic, and make inadequate immune responses particularly to encapsulated organisms, so suffer from recurrent sinopulmonary bacterial infections. In addition, they have an increased risk of developing autoimmune disease, including autoimmune haemolytic anaemia, and neoplasia. ${ }^{2}{ }^{3}$ Treatment includes IVIG and prompt antibiotic therapy for infections. It is important to remember that serological testing is usually inappropriate in CVID because these patients cannot mount an adequate humoral immune response to infection. Instead, direct identification of the patho-

1 Herriot R, Gray ES. Images in clinical medicine: owl's eye cells. N Engl F ES. Images in clinical medicine: owl's eye cells. N Engl F Med 1994;331:649.

Hermaszewski RA, Webster ADB. Primary hypogammaglobulinaemia: a survey of clinical manifestations and complications. $Q \mathcal{F}$ Med 1993;86:31-42.

3 Cunningham Rundles $\mathrm{C}$. Clinical and immunologic analyses of 103 patients with common variable immunodeficiency. $\mathcal{F}$ Clin Immunol 1989;9:22-33.

\section{Learning points}

- serological tests are not helpful in antibodydeficient patients; culture, direct visualisation of the pathogen, or PCR-based techniques are required

- in immunodeficient patients who also receive immunosuppressive therapy (eg, steroids) extra vigilance is required for opportunistic pathogens

genic organism is required, even if (as in this case) invasive procedures are required to obtain specimens. Despite earlier suggestions of $\mathrm{CMV}$ being implicated in $\mathrm{CVID}^{4}$ recent studies using a highly sensitive nested polymerase chain reaction (PCR) assay refute the previously reported increase in active $\mathrm{CMV}$ infection in CVID. ${ }^{5}$ Although CVID patients often show in vitro evidence of cell-mediated immune dysfunction, clinical CMV infection is unusual. In this case, however, the patient had additional immunosuppression secondary to the steroid therapy for his autoimmune haemolytic anaemia. The combination of a primary and an iatrogenic immunodeficiency prompted the aggressive search for a causative agent using non-serological techniques.

\section{Final diagnosis}

Cytomegalovirus pneumonitis.

Keywords: common variable immunodeficiency; cytomegalovirus pneumonia; hypogammaglobulinaemia

The micrograph was kindly supplied by Dr Winifred Grey, Department of Cellular Pathology, John Radcliffe Hospital, Oxford

4 Docke WD, Simon HU, Fietze E, et al. Cytomegalovirus infection and common variable immunodeficiency. Lancet 1991;338:1597.

5 Mullighan CG, Read SJ, Bird AG, Kurtz JB, Chapel HM, Welsh KI. Human cytomegalovirus infection is not increased in common variable immunodeficiency. $f$ Clin Immunol 1996;16:272-7. 